\title{
¿PARA QUÉ MAESTROS Y MAESTRAS EN TIEMPOS DE CONFINAMIENTO?'
}

Mónica Moreno Torres ${ }^{2}$

Elvia Adriana Arroyave Salazar ${ }^{3}$

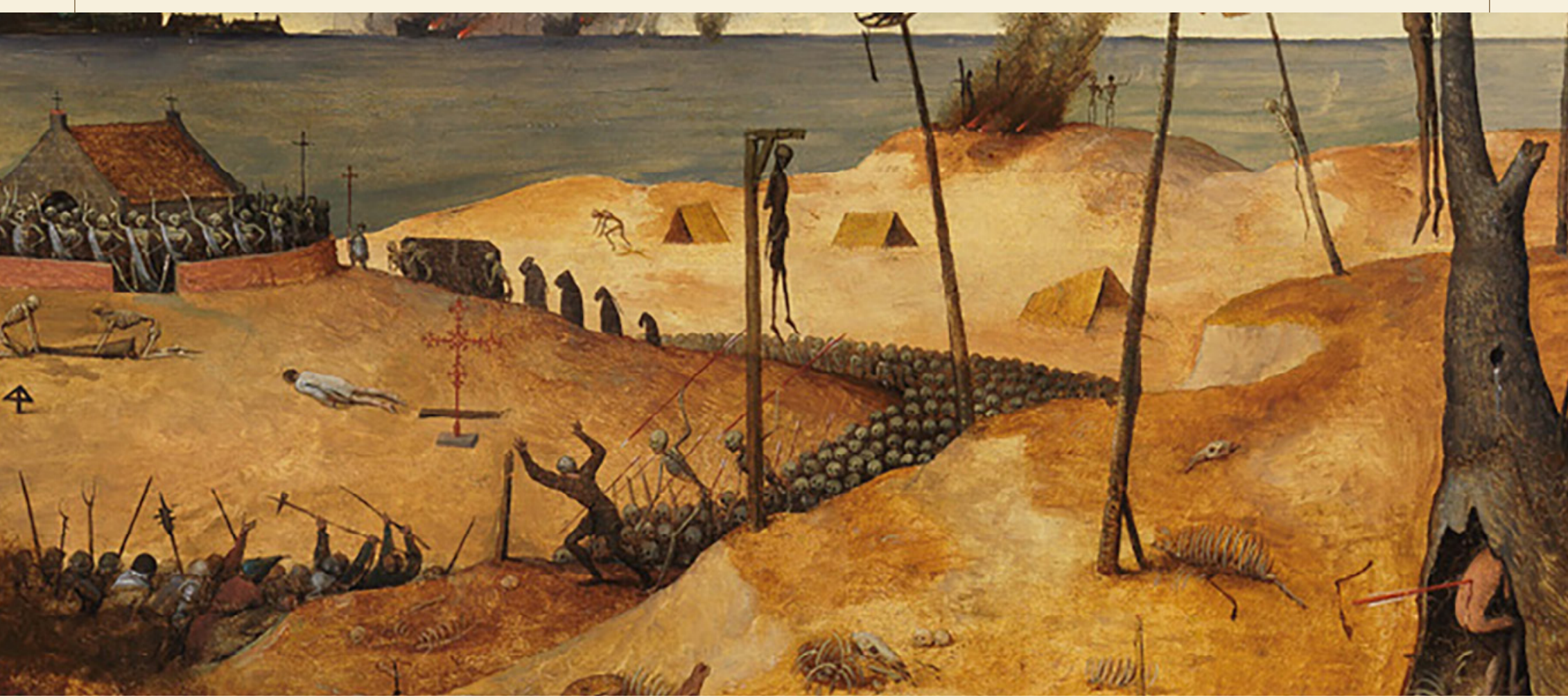

1 El presente artículo forma parte de la tesis doctoral "El taller de Adria[d]na. Entre CostURAS: Punto - cadeneta -afecciones. Tejidos de una Costuromaestra" y del proyecto "Educar en tiempos de convivencia: de las corpo-realidades en el aula" financiado por el CODI-Universidad de Antioquia-Colombia

2 Doctora en Educación. Profesora de la Facultad de Educación de la Universidad de Antioquia y asesora de prácticas. Coordinadora del grupo de investigación Didáctica de la Educación Superior DIDES. Correo electrónico: monica.moreno@udea.edu.co ORCID https:/ orcid.org/0000-0002-7600-7706

3 Candidata a Doctora en Educación. Profesora de cátedra de la Facultad de Educación de la Universidad de Antioquia e integrante del Grupo de Investigación Estudios en Educación Corporal. Correo electrónico: elvia.arroyave@udea.edu.co ORCID https:/ orcid.org/0000-0001-7821-1949

Cómo citar: Moreno Torres, M., Arroyave Salazar, E. A. (2020). ¿Para qué maestros y maestras en tiempos de confinamiento?. Enunciación, 25(2, separata), XXXI-XXXVII. https://doi.org/10.14483/22486798.17014 


\section{Introducción}

Pan y vino

Es mejor dormir, a existir así sin compañeros, A esperar así y qué hacer entre tanto y qué decir Yo no sé y ¿para qué poetas en tiempos mezquinos? Pero ellos son, dices tú, santos sacerdotes como el dios del vino,

Que de tierra en tierra transitaron en noche santa

Hölderlin (1951, citado por Vivas, 2020).

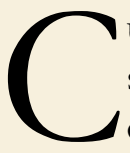
uando Hölderlin pone en estado de cuestión la presencia de los poetas en tiempos mezquinos, lo hace movido por los siguientes acontecimientos: 1) considera que dormir es sinónimo de callar y 2) compañeros son aquellos poetas que, atraídos por el dinero y la fama, abandonaron el compromiso con dicho arte. Mezquindad es "la destrucción de la tierra [que] iba acompasada de la degradación ética de los humanos" (Vivas, 2020, p. 22) y a los sacerdotes y los dioses los hace comparables con el poeta, la religión y lo místico.

Considera también que mientras el humano separa, el poeta reúne lo disperso en busca de su armonía (p. 46) con la naturaleza; pues tiene la posibilidad de mostrar el deterioro de los ecosistemas, sacándolos de su olvido (p. 45) y para el caso la religión sería la encargada de enseñar al bumano además de un mundo más elevado, el asombro del planeta (p. 44). Finalmente, consideraba el poeta que, para los dioses griegos, los humanos no eran confiables ni entre ellos mismos y entre las otras especies (p. 38), debido a su injerencia en las problemáticas de la sociedad.

Hölderlin, en su crítica a los poetas y la sociedad, también incluía a la escuela y a la razón ilustrada. De allí que se pregunte ¿por qué la escuela de los bumanos forma para el trabajo y deja de lado la enseñanza y el aprendizaje de una vida nutricia? (p. 31, el subrayado es nuestro). En el caso de la ilustración, advierte que el autoritarismo de la razón, al estar apoyado en el miedo y la obediencia, pone en peligro el desarrollo del cuerpo, la imaginación, el arte y la felicidad de quienes se forman allí (p. 54).

Lo anterior es muy cercano a lo que nos sigue ocurriendo en este siglo XXI. Bastó un acontecimiento mundial como la expansión del covid-19, para que la sociedad planetaria recordara que el deterioro de los ecosistemas sigue en aumento. Mientras el encierro de los habitantes en sus casas ha sido una de las estrategias para evitar la expansión del virus; el hábitat de los animales y los diversos ecosistemas mares, ríos, selvas y plantaciones- empezaron a restaurarse. Así mismo, se evidenció cómo la internacionalización de la ciencia, la educación, el arte, la política, la economía y las tecnologías de la información y la comunicación (TIC), al ser apéndices de los defensores de las políticas neoliberales, seguía imponiendo el miedo y la obediencia a los que se refiere el poeta alemán.

El miedo y la obediencia ocasionadas por la expansión del virus han hecho presencia de diversos modos. Para algunos, y en palabras de Hölderlin, había que descreer de los humanos, pues ni entre ellos mismos, esto es, los gobernantes mundiales, se han puesto de acuerdo en relación con las medidas que se debían y deben adoptar cara a la pandemia; y en lo que respecta a la escuela, la estrategia de confinamiento era urgente, debido al hacinamiento que históricamente ha distinguido a la mayoría de los establecimientos de educación pública ${ }^{4}$. No obstante, gobernantes

4 El hacinamiento, además de su relación con la arquitectura panóptica de la mayoría de los establecimientos de educación pública del país, provoca en los estudiantes cuerpos constreñidos, expuestos a la mirada de las directivas y profesores cuando se asumen como censores; ¿Quién vigilaría los cuerpos de los estudiantes que estaban confinados en sus casas? ¿Qué pasaría con los procesos de evaluación? Como bien lo expresa Rodríguez (2004), "uno de los dispositivos favoritos de las técnicas disciplinarias es el examen" (pp. 12-13); ¿se podría dejar de lado la evaluación por competencias en la escuela?; ¿qué pasaría con la evaluación por resultados de aprendizaje que el MEN en su Decreto 1330/2019, le viene exigiendo a las Facultades de Educación para otorgarles la renovación del Registro Calificado de los programas? Si al culminar el confinamiento, la evaluación 
y encargados de la educación, coincidían en la necesidad de impulsar el uso de las TIC, para darle continuidad al proceso de formación de los estudiantes.

Nuevamente, las promesas que en época de campaña y posesión hicieron la mayoría de los políticos, ministros de Educación y de Tecnología a la ciudadanía en relación con la dotación, uso, acceso y conectividad de los estudiantes, se cayeron de su peso. Los profesores se vieron impelidos a recibir cursos relámpago en el uso de las TIC; recurrieron a plataformas educativas oficiales y de acceso libre para el diseño y desarrollo de las actividades con los estudiantes, las cuales dejarían por fuera por lo menos el $78 \%$ de ellos (El Espectador, 2020); las guías didácticas en la escuela y los programas de curso en la universidad fueron reconfigurados con base en una didáctica situada que reconocía los ritmos de aprendizaje y los contextos de los estudiantes 5 . En ese sentido, nuevamente el magisterio colombiano y el profesorado universitario fueron resolviendo algunas de las problemáticas que la educación a distancia, remota o virtual les demandaban.

Decimos algunas, pues las relacionadas con el acceso y conectividad de los estudiantes en el caso de la universidad pública colombiana se resolvieron parcialmente. $\mathrm{Al}$ respecto, el rector de la Universidad de Antioquia señala que por lo menos el $25 \%$ de los estudiantes se quedaría por fuera del sistema educativo (Dinero, 2020), debido a la falta de equipos electrónicos. A estas problemáticas, se sumaron las condiciones socioeconómicas de sus familias y el estado anímico de los estudiantes. Esto hizo que la demanda de los

de los aprendizajes como ejercicio de medición y control sigue presente en las prácticas pedagógicas de la escuela y la universidad, vale la pena preguntarse: ¿Seguiremos durmiendo como lo dice Hölderlin en su poema "Pan y vino"?; ¿no tendremos compañeros que, reunidos en cuerpo docente, hagan posible el advenimiento de una poética planetaria?, a la que nos vamos a referir más adelante.

5 Las guías escolares impresas eran reclamadas en la institución educativa por los padres de familia, cuidadores, y voluntarios. Estos últimos, eran personas que, al prestar un servicio público en las comunidades rurales, tenían la posibilidad de hacerlas llegar a los estudiantes. Su compromiso con la escuela es narrado por los maestros. programas de bienestar universitario y la atención psicosocial dirigida a los estudiantes aumentaran. Asimismo, puso a los profesores que estábamos encargados de la formación de maestros en un proceso de resignificación de las prácticas pedagógicas, que se convirtió, parafraseando a Hölderlin, en la posibilidad de enseñar a este grupo de bumanos, la esperanza en un mundo más elevado, donde el asombro del planeta, lo vivimos en la perspectiva de una Poética planetaria (Universidad de Antioquia - Facultad de Educación, 2020a) ${ }^{6}$.

¿Cómo avanzamos en esta intención? Cuándo el título de este texto es precisamente "¿Para qué maestros y maestras en tiempos de confinamiento?". Un entresijo que se coló en el silencio desde el inicio de este aislamiento, un interrogante que surgió al escuchar el sentir de los maestros en formación (MF): ¿para qué seguir estudiando si no tenemos escuelas, si no hay aulas, si no hay estudiantes, si no hay cuerpos presentes en las escuelas? Un entresijo que sirvió para hacerle quite al miedo y a la obediencia para darle cabida al cuerpo que se hace extensión (Eslava, 2010), a través de la pantalla, para darle paso al desconfinamiento de la palabra y hacer del cuerpo del MF un cuerpo de la experiencia (Castro y Farina, 2015).

$[\ldots]$ pero en la ventana pequeña de la sala pequeña de mi casa pequeña cabe una MONTAÑA.

\section{Alejandro Foronda Sierra. Práctica Pedagógica I 2020-I}

6 El video Diálogos entre la literatura y las ciencias. Defensa de la tesis doctoral del profesor Norberto Caro (Universidad de Antioquia - Facultad de Educación, 1 de septiembre de 2020) presenta, entre el minuto 46:46 y el 50:54, una carta titulada "Estásimo tres. Lo que le dijo un didacta a Isaac Asimov del advenimiento de una poética planetaria”. $\mathrm{Al}$ respecto, dice: "¿Qué pasará cuando termine el confinamiento, estimado Isaac? Además del aprendizaje que recibimos de los ecosistemas inteligentes del planeta, ¿los educadores nos daremos a la tarea de formar a las nuevas generaciones de científicos, artistas, gestores sociales y políticos, y maestros en relación con una nueva ética, otras estéticas y otra visión política? Está abierto el espacio para que la razón poética, la razón creativa y la razón sensible reconfiguren una poética planetaria". 


\section{El cuerpo del maestro se hace experiencia y abre la ventana al desconfinamiento de la pal- abra: entre Prácticas Pedagógicas I y IV}

De este modo, advertir en los MF que la escuela podía mudarse a la casa y con ella el aula de clase para hacerse habitable como espacio poético, "una forma simbólica en la que se inscribe la intimidad de la experiencia escolar" (Zuluaga Giraldo y García Restrepo 2013, p. 197) y así hacer del aula virtual un lugar vivo, creativo y más humano; donde los MF de Práctica Pedagógica I sean los protagonistas y así coincidir en la metáfora "La casa como un espacio de formación"”. Acudir a esta figura posibilitó dar continuidad al eje "Yo como centro de práctica. Mi cuerpo como centro de práctica"; promovido desde el núcleo de práctica y planteado para la Práctica Pedagógica I y que se unió al entresijo “¿Qué mediaciones pedagógicas se hacen presentes hoy en mi centro de práctica, desde la cotidianidad del espacio que habito -la casa-?" y cómo este presente invitó a los MF a mirar desde otro lugar el confinamiento que hoy se vive desde una experiencia transformadora de vida.

La pregunta "¿Para qué maestros y maestras en tiempos de confinamiento?” cobró sentido, pues los estados anímicos y corporales de estos, se hicieron extensión para transcribirse ahora en mediaciones estéticas" "lo que soy / lo que elegí ser / lo que quiero llegar a ser. Todo lo anterior, mi cuerpo lo resiste / lo acepta / lo interioriza" (Taborda Carmona, 2020). Reconocer su cuerpo como su propio centro de práctica es darle cabida al cuerpo de la experiencia pues este "tiene que ver con un cuerpo experiencial, plural

7 Esta metáfora fue creada por la asesora de Práctica I, Adriana Arroyave Salazar, para el curso una vez se ordenó el confinamiento de parte del Gobierno nacional cara a la situación de salud pública que hoy se enfrenta.

8 Los maestros en formación acudieron a diferentes mediaciones estéticas como el tejido, la pintura, el video, la elaboración artesanal de libro, la grabación de videos y creaciones literarias para dar respuesta al eje: Reconocer al yo soy mi centro de práctica y trabajar el cuerpo del maestro como extensión. Para hacer del cuerpo un lugar de la experiencia. y múltiple, un cuerpo a la vez material y energético, racional y emocional, sensible y extensivo, personal y vincular, real y virtual" (Castro y Farina, 2015, p. 182). El MF capaz de reconocer que, en su voz, en su cuerpo y en sus maneras de afectarse está el primer centro de práctica es capaz de comprender que su cuerpo no solo está hecho de materia sino también de lo no material; de lo que no se toca y se puede sentir pues "los cuerpos están en variación afectiva. Lo que nos alegra hoy mañana nos puede entristecer" (Restrepo Tous, 2020).

Llevar el aula de clase a la casa posibilitó en los MF intensificar su mirada y comprender que es un espacio para dar rienda suelta al primer centro de práctica, como bien lo expresa Noel Arnaud: "Yo soy el espacio donde estoy" (citado por Bachelard, 2000, p. 128); hacer de la casa un entorno de formación, humanizante y humanizado para comprender que el aula de clase y la escuela también se alojan y se llevan en el cuerpo; un cuerpo presente que se presta atención. Al final, este confinamiento se mostró como un bello bálsamo para los MF de Práctica Pedagógica I. Su cuerpo se hizo experiencia en la mirada, en la escucha, en el gesto, en la mano inquieta que dejó deslizar el trazo con libertad para dejarse conducir por el camino de una vocación que asoma tras la ventana. "Mi casa es pequeña / tiene una sala pequeña / y en la sala / hay una ventana pequeña" (Foronda Sierra, 2020)

En este punto de la narrativa, seguir con la educación en casa de los MF de Práctica Pedagógica IV, o "La clase en pantuflas" como lo dice Dussel (Canal ISEP, 2020); clase que ha ocasionado un borramiento de fronteras entre la escuela y la casa. Esta situación nos llevó a proponerles a los MF Práctica Pedagógica IV que, ante la adversidad que nos asistía, era necesario otorgarle a la palabra el lugar que históricamente la había distinguido, y la mejor manera de hacerlo, de recuperarla, era trayéndola de la mano del prefijo des-: ¿Desconfinados de la palabra y de la acción? 
(Universidad de Antioquia - Vicerrectoría de Docencia, 6 de agosto de 2020) ${ }^{9}$. Prefijo e interrogante que sirvió para proponer una ruta de formación a los MF de Práctica Pedagógica IV y que incluyó momentos como: 1) La identificación de un hecho sorprendente, que surgió de las sensaciones anímicas y corporales del maestro en formación, provocadas por el estado de confinamiento que se vive hoy. Asunto que sería susceptible de traducirse en un proceso de mediación estética por medio de la interacción con los niños de la escuela donde adelantaron la práctica pedagógica (virtual o remota). 2) La sustentación teórica del hecho, que se realizó con base en los tres modos de la ražonabilidad peirceana ${ }^{10}$ : la abducción, la deducción y la inducción, que confluyeron en la formulación de una hipótesis abducti$\mathrm{va}^{11}$. Aunada al estudio de la bibliografía del curso cuyo tema central era la formación de lectores literarios infantiles. 3) La creación de una estrategia didáctica que inclúa: la problematización del hecho sorprendente, la conversación como horizonte didáctico y hermenéutico, la justificación, la sustentación de la hipótesis abductiva, y la mediación estética. "[...] la mediación didáctica consiste en suministrarle al alumno la información de la que no dispone y que no podría procurarse por sus propios medios" (Not, 1992, p. 83); para el caso, la mediación estética transforma la información en un proceso sensible de cognición, permitiéndole al

9 Véase en el canal de Udearroba, la lectura de la ponencia "Persistencias y resistencias en la formación estética y política de los futuros maestros: a propósito del desconfinamiento de la palabra" (Universidad de Antioquia - Vicerrectoría de Docencia, 6 de agosto de 2020).

10 La razonabilidad consiste en incentivar en los estudiantes "sus capacidades (imaginación, abducción e identificación de un problema) y actitudes, sumadas a la creación de un entorno creativo en el aula (Barrena, 2008, citada por Moreno Torres y Carvajal Córdoba, 2015, p. 179). "Sin imaginación, no sería posible la construcción de ninguna hipótesis científica” (Barrena, 2007, p. 109).

11 Los maestros en formación escribieron los tres modos de razonamiento en busca de la hipótesis abductivas y, a pesar del malestar que ello les ocasionó, llegaron a la creación de diversas mediaciones estéticas. Posiblemente, porque en los seminarios y asesorías les decía que "la hipótesis es una búsqueda sinuosa e interminable"; por tanto, un proceso de fascinación razonable y sensible.
MF convertirse en un escritor en formación, pues ha configurado un mundo posible.

En relación con la mediación estética se exponen grosso modo cinco procesos de creación literaria ${ }^{12}:$ 1) una de las MF se pregunta: “ ¿Cómo abordar en el proceso de formación de lectores literarios infantiles el tema de la muerte?" (Zapata Pérez, 2020). 2) Dos MF adelantan su práctica en institución educativa de carácter rural (IER); allí una de las maestras preocupada por la contaminación que produce el desecho de los tapabocas, se pregunta ¿dónde nace el océano? (Barragán Vergara \& Zapata Pérez, 2020). 3) un MF al conocer diversas concepciones en relación con la multiculturalidad, se propone indagar por cuál de ellas enseñar (Benítez Suárez, 2020). 4) Una MF se interroga: “¿Cómo se acerca un saber a los niños y a sus hogares desde el amor, la comprensión y la flexibilidad curricular?" (Villa, 2020). 5) Una MF motivada por la lectura que realiza de un poemario infantil quiere saber: "¿Por qué hemos descuidado hasta el punto de la crueldad o la indiferencia, el trato que les damos a los animales?" (Restrepo Henao, 2020).

\section{Conclusiones}

Detenerse y prestar-se atención para escuchar lo que el cuerpo tenía para decir respecto a la Práctica Pedagógica I y al fundamento que los reunía, "yo como centro de práctica", y asimilar cómo el cuerpo es un buen lugar para sentirpensar el espacio de aula de clase y de la escuela. Llevar el aula de clase a la casa no silenció el cuerpo, al contrario, lo hizo extensión a través de la pequeña ventana virtual; lo nutrió con imágenes no vistas y mediaciones estéticas que fueron creadas y motivadas por los encuentros que se nutrían de un presente incierto que nos preguntaba: ¿Para qué maestros y maestras en tiempos de confinamiento?,

12 Véase Universidad de Antioquia - Facultad de Educación. (2020b). Experiencias de Prácticas I y IV semestre 2020-1 
para acompañar y "educar en vocación [...] [;] la vocación es esencialmente mediadora. $\mathrm{Y}$ es el maestro quien, sobre todos, ejerce una función mediadora de carácter social" (Casado y Sánchez-Gey, 2011, p. 7).

Los MF de Práctica Pedagógica IV se vieron impulsados a modificar su concepción en relación con la formación de lectores literarios infantiles, pues se encontraban en los bordes de una escuela remota, que jamás habían imaginado y se les imponía como un ritual de salvación; no solo por la defensa de la vida debido a la existencia del virus, sino también, y como lo expresa (Freire, 2012), porque se encontraban en un estado de incertidumbre que los convoca al "ejercicio de la curiosidad, a la imaginación, a la intuición, a las emociones, a la capacidad de conjeturar, de comparar" (p. 83). Todo ello con la intención de hallar un objeto sensible de cognición que hiciera posible la emergencia de una rarón sensible, como diría Maffesoli (1997), en busca del desconfinamiento de la palabra.

\section{Referencias bibliográficas}

Areiza Osorio, S (2020). Carta de mi para mí. Universidad de Antioquia - Facultad de Educación. Recuperado de https://bit. $1 y / 3 \operatorname{erg} K M w$

Bachelard, G. (2000). La poética del espacio. Fondo de Cultura Económica.

Barragán Vergara, M. A., y Zapata Pérez, M. A. (2020). El Fluir de la vida. Universidad de Antioquia - Facultad de Educación. Recuperado de https:// bit.ly/3ergKMw

Barrena, S. (2007). La razón creativa. Crecimiento y finalidad del ser bumano según C. S. Peirce. Rialp.

Barrena, S. (2008). Charles S. Peirce: razón creativa y educación. Utopía y Praxis Latinoamericana, 40, 11-38. Recuperado de https:// www.redalyc.org/pdf/279/27904002.pdf

Betancur Correa, V (2020). Contar hasta 5. Universidad de Antioquia - Facultad de Educación. Recuperado de https://bit. ly/3ergKMw
Canal ISEP [Instituto Superior de Estudios Pedagógicos] (23 de abril de 2020). La clase en pantuflas | Conversatorio virtual con Inés Dussel | ISEP [Archivo de video]. Recuperado de https:/ / www. youtube.com/ watch? $\mathrm{v}=6 \mathrm{xKvCtBC3 \textrm {Vs }}$

Casado, A. y Sánchez-Gey, J. (2011). Filosofía y educación en María Zambrano. Manuscritos. Revista Española de Pedagogia, 65(238), 545-557 Recuperado de http://www.jstor.org/ stable/23766065

Castro, J. y Farina, C. (2015) Hacia un cuerpo de la experiencia en la educación corporal. Revista Brasileira de Ciências do Esporte, 37(2), 179-184. DOI: https://doi.org/10.1016/j.rbce.2014.02.002

Dinero (25 de junio de 2020). Aprendizajes y retos de la educación superior en tiempos de coronavirus. Revista Dinero. Recuperado de https://www.dinero.com/pais/articulo/aprendizajes-y-retos-de-la-educacion-superior-frente-al-coronavirus / 290635

El Espectador (13 de marzo de 2020). Los colegios públicos de Colombia no están preparados para dar clases virtuales. ElEspectador.com. Redacción Educación. Recuperado de https://www. elespectador.com/coronavirus/los-colegios-publicos-de-colombia-no-estan-preparados-para-dar-clases-virtuales-articu$10-909149 /$

Eslava, E. (2010). Movimiento, espacio, extensión: Spinoza y la mecánica de los cuerpos. Universitas Philosophica, 27(54), 109-119. Recuperado de http://www.scielo.org.co/scielo.php?scrip$\mathrm{t}=$ sci_arttext\&pid=S0120-53232010000100006\&lng=en\&tln$\mathrm{g}=\mathrm{en}$

Foronda Sierra, A (2020). Mi casa. Universidad de Antioquia - Facultad de Educación. Recuperado de https://bit.ly/3ergKMw

Freire, P. (2012). Pedagogía de la autonomía: saberes necesarios para la práctica. Siglo XXI Editores.

Maffesoli, M. (1997). Elogio de la razón sensible. Una visión intuitiva del mundo contemporáneo. Paidós.

Ministerio de Educación Nacional [MEN]. (25 de junio de 2019). Decreto 1330 de 2019. Recuperado de https://www.mineducacion.gov.co/1759/articles-387348_archivo_pdf.pdf 
Moreno, M. y Arroyave, E. (2020). Casa Algodón_PGCA_10_09_20. Universidad de Antioquia - Facultad de Educación. Recuperado de: https://bit.ly/3ergKMw

Moreno Torres, M. y Carvajal Córdoba, E. (2015). La confluencia de los tiempos de la investigación con diversos sujetos dialógicos y escenarios socioeducativos. En V. E. Espinosa Galán (ed.), Bases de una estrategia didáctica para la formación de profesores investigadores (pp. 147-220). Bogotá: Editorial Aula de Humanidades.

Not, L. (1992). Parte segunda: la enseñanza dialogante. En La enseñanza dialogante. Hacia una educación en segunda persona (pp. 71-83). Barcelona: Editorial Herder.

Penagos Sánchez, R (2020). El oficio de ser maestros. Textos inéditos: entre el cuerpo y la casa. Universidad de Antioquia - Facultad de Educación. Recuperado de https://bit.ly/3ergKMw

Restrepo Henao, S. (2020). Video de práctica. Universidad de Antioquia - Facultad de Educación. Recuperado de https://bit. ly/3ergKMw

Restrepo Tous, S. (2020). Co-siendo libro. Textos inéditos: entre el cuerpo y la casa. Universidad de Antioquia - Facultad de Educación. Recuperado de https://bit.ly/3ergKKMw

Rodríguez, M. (2004). Novela y poder: el panóptico. La ciudad apestada. El lugar de la confesión. Atenea, 490, 11-32. https:// scielo.conicyt.cl/scielo.php?script=sci_arttext\&pid=S0718 $-04622004049000002$

Taborda Carmona, C. (2020). La autoposia y Liciernagas. Universidad de Antioquia -Facultad de Educación. Recuperado de https:// bit.ly/3ergKMw
Universidad de Antioquia - Facultad de Educación (1 de septiembre de 2020a). Diálogos entre la Literatura y las Ciencias. Defensa de la tesis doctoral del profesor Norberto Caro [Archivo de video]. https:/ / www.youtube.com/watch? $\mathrm{v}=\mathrm{GB} 75 \mathrm{rcSH}$ YM M \&eature=youtu.be

Universidad de Antioquia - Facultad de Educación (4 de noviembre de 2020b). Experiencias de Prácticas I y IV Semestre 2020-1 [Archivo de video] https:// bit.ly/3ergKMw

Universidad de Antioquia - Vicerrectoría de Docencia [Udearroba] (6 de agosto de 2020). Lección inaugural: Socialización Trabajos de grado Facultad de Educación [Archivo de video]. https:/ / www.youtube.com/watch?v=QUe_GtrKgSE

Villa, C. (2020). El ángel y el gato. [Audiolibro]. Universidad de Antioquia - Facultad de Educación. Recuperado de: https://bit. ly/3ergKMw

Vivas, S. (marzo de 2020). Pan y vino. Ensayo sobre un poema de Hölderlin. Universidad de Antioquia.

Zapata Pérez, M. A. (2020). Otto, el carpintero desafortunado. Universidad de Antioquia - Facultad de Educación. Recuperado de: https://bit.ly/3ergKMw

Zuluaga Giraldo, C. y García Restrepo, G. del S. (2013). María Zambrano: una nueva fenomenología acerca de la educación. Praxis Filosófica, (37), 193-208. https://www.researchgate.net/profile/Conrado_Zuluaga/publication/317505723_ Maria_Zambrano_a_new_phenomenology_about_edu cation/links/5c8bb4f1299bf14e7e7e3fef/Maria-Zambra no-a-new-phenomenology-about-education.pdf

\section{(c) $(1)(0$}

[XXXVII]

ISSN 0122-6339 • ISSNe 2248-6798 • Vol. 25, No. 2 (julio/diciembre de 2020) • Separata. 